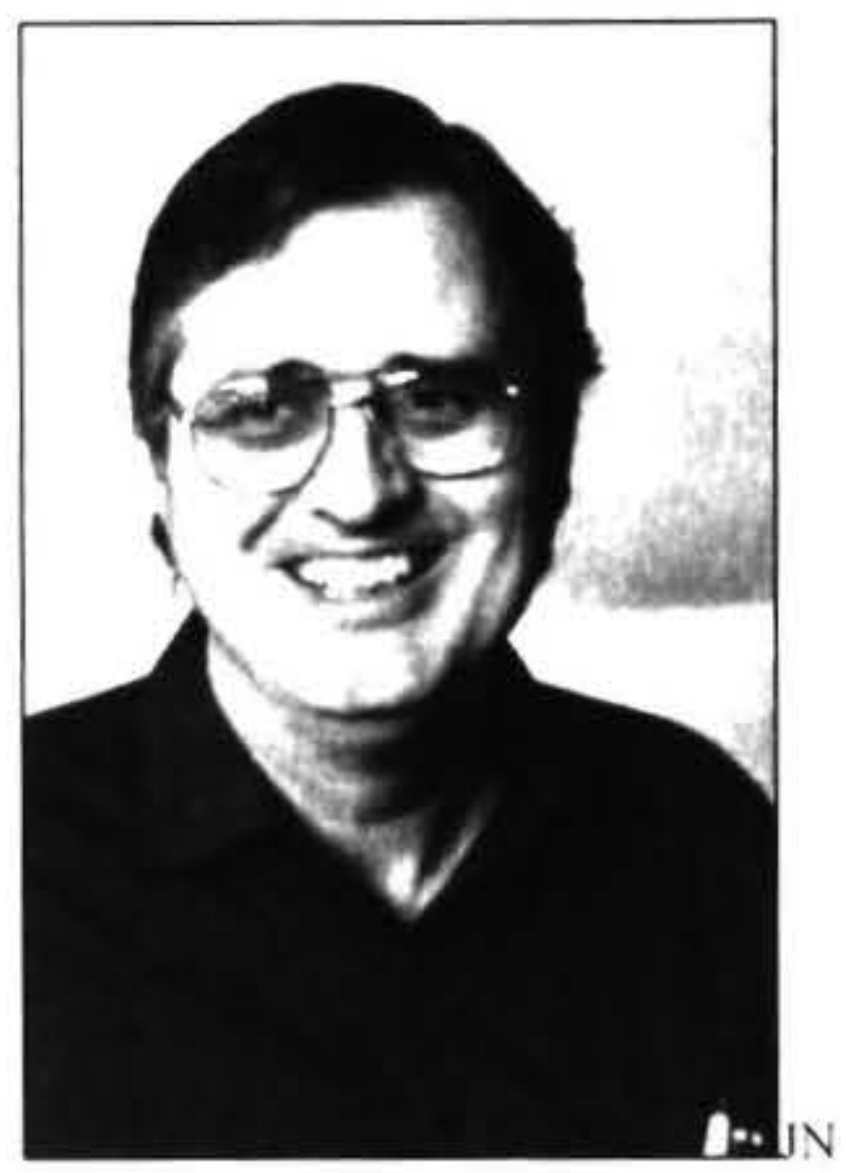

\title{
VARIATION IN MULTIPLE JOB HOLDING RATES AMONG WOMEN WITH YOUNG CHILDREN AS AN INDICATOR OF WORKLIFE BALANCE
}

\author{
James Newell \\ Monitoring \& Evaluation Research \\ Associates, Wellington
}

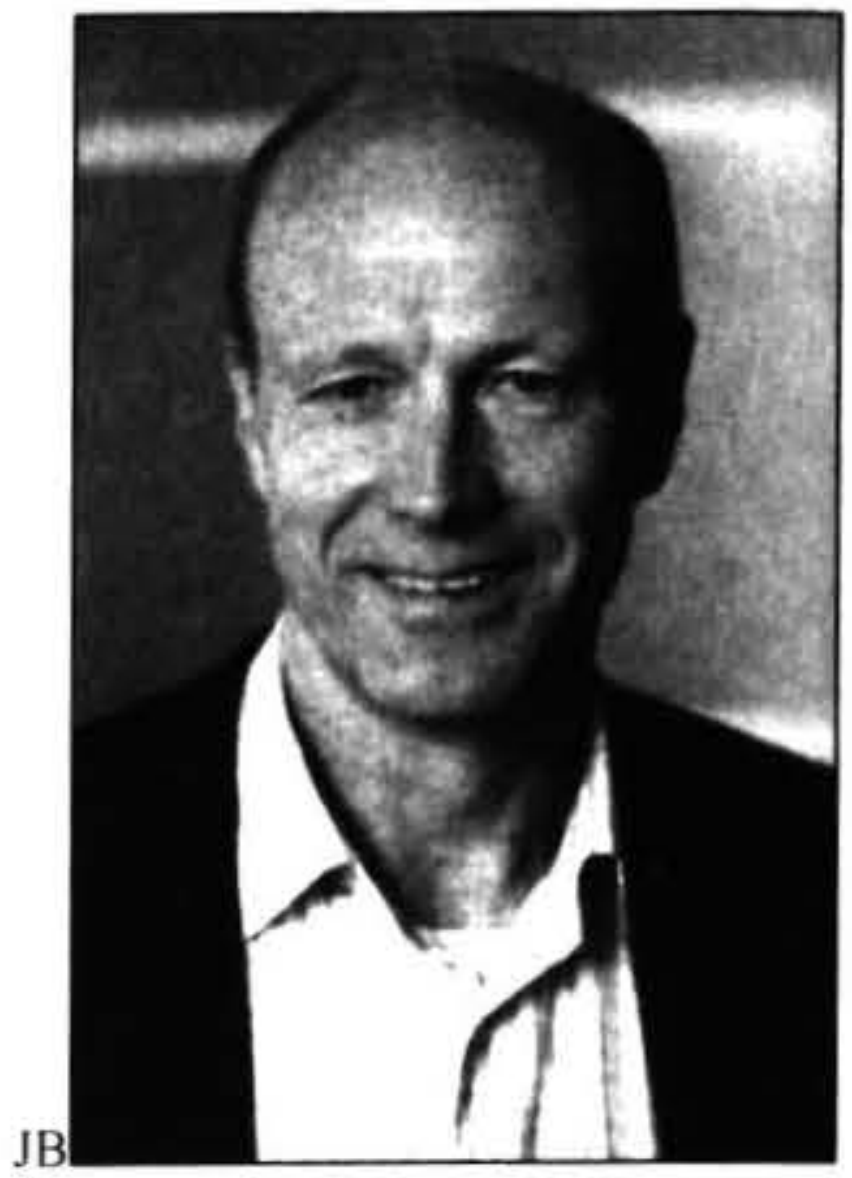

\section{James Baines}

Taylor Baines \& Associates, Christchurch

\begin{abstract}
This paper presents 1981 to 2001 census statistics on multiple joh holding rates of women living in households with children under wo by women's age and occupation as an indicator of work life balance issues. Trends in multiple job holding rates by women living in households with children under wo are compared with multiple job holding rates for women in other npes of households. Multiple job holding hy women living in households with children under two peaked in 1996. Multiple joh holding rates by women aged 20 to 29 years living in households with children under two are almost identical to those for all working women aged 20 to 29 years but tend to be much lower for women of other age groups. The margin hetween multiple joh holding rates of women living in households with children under two and others tends to be higher for high socio-economic status than low socio-economic status occupations. This suggests that economic and career pressures on work life halance are highest in roung adulthood when women are juggling entry into the work force, family formation and the costs of setring up their own households. Financial pressures to remain in the work force with roung childre'n impose stronger work life balance pressures on families on low incomes rather than those of higher income professionals.
\end{abstract}

\section{Introduction}

In the Census of Population and Dwellings, the question is asked "In the 7 days that ended on .... did you have one job or more than one job?" Those with more than one job are defined as multiple job holders. This includes those whose first or second job was "unpaid work in a family business". This paper uses a range of statistics on multiple job holding derived from the census to explore the evidence for work life balance tradeoffs associated with individuals "choice or necessity" to be multiple job holders.

This paper focusses in on multiple job holding by women in household association with young children. What clues does variation in multiple job holding by women with young children in this context offer of work-life balance tradeoffs associated with this significant and in some areas still rapidly growing work strategy (refer Baines and Newell, 2005)? '

The paper has been prepared as part of a FRST research programme into multiple job holding. The objectives of this funded research programme are to:
* determine the extent and nature of multiple job holding in New Zealand society as a change strategy for individuals, families and communities; and

* identify the factors which encourage or inhibit the adoption of multiple job holding as a change strategy.

Engagement in multiple job holding activity, as measured in the census, grew from $4.2 \%$ of the working population in 1981 to $10.1^{\circ} \%$ in 2001 (Baines and Newell, 2005). Multiple job holding grew both in a period of severe labour market contraction (1986 to 1991) and expansion (199| to 1996). Overall national multiple job holding rates stabilised between 1996 and 2001 at around $10 \%$ for the working population. This equilibrium masks growing divergence between main urban labour markets and rural labour markets. Between 1996 and 2001, multiple job holding rates in main urban areas decreased slightly from 9.0 to $8.2 \%$ but grew from around $16 \%$ to around $20 \%$ in rural areas (Taylor, Baines and Newell, 2006). In 2001, around one in five employed persons in rural New Zealand was a multiple job holder.

Summarising the effects of multiple job holding on the lives of workers in three sectors, McClintock, Taylor and Warren (2004) observed that "multiple job holding affects 
lives outside work, particularly family activities, participation in leisure and exercise, and community involvement". These effects on work-life balance vary by sector.

Work life balance has received considerable attention over the last few years as women's participation in the formal labour force has increased substantially. Work-life balance "means different things to different people and their organisations". ${ }^{2}$ UMR Research (2003) used a range of focus groups and five in-depth interviews with employers to explore current understanding and attitudes towards the issue of work-life balance. Participants reported three components that participants felt needed to be in balance to achieve a healthy lifestyle, namely, paid work, unpaid work and personal time.

Callister (2005) analysed census data on changes in paid work by women and men between 1986 and 2001, finding that although average hours changed very little, there was a "polarisation" of total hours worked. The proportion working shorter and longer total hours increased at the expense of those in the middle of the total hours distribution. He found that total hours worked by couples with young children had increased.

Women's Affairs (2002a) analysed 2001 census data on employment of mothers with a young child under 5 , finding that $33 \%$ of European solo mothers and $56 \%$ of European partnered mothers were employed. In a NZ jurisdictional report "Work and Family Balance : A Policy Perspective", Women's Affairs (2002b) comment that mothers with a child under five tended to work shorter hours than those whose young child was over five.

The results presented here start with an overview of overall trends in total hours worked leading through to the differences in total hours worked revealed by census labour force time series analysis. It leads on from this to consideration of total hours worked by multiple job holders versus others. Trends in multiple job holding rates by age of women and age of youngest child are then analysed. Finally, differences by occupation in multiple job holding rates by women with young children are presented and possible explanations considered. Unless otherwise specified, all tables included in this report are derived from custom tabulations of the census of population and dwellings carried out by the authors.

\section{Trends in Total Hours Worked}

Overall mean total hours worked dropped significantly from 41 hours in 1986 to 36.9 in 1996 and then recovered slightly to 37.6 hours in 2001 (Table 1). These aggregate changes mask contrasting trends for different age bands, sexes and subgroups.

Changes in total hours worked by males varied little in a narrow range between 45.1 and 45.5 hours and females more widely in the range 33.2 to 34.7 between 1981 and 2001. Overall total hours decreased between 1986 and 1996 as the proportion of women in the work force increased, working fewer hours on average than their male counterparts.

Table 1: Trends in employed male and female mean total hours worked 1981 to 2001.

\begin{tabular}{llllll} 
& 1981 & 1986 & 1991 & 1996 & 2001 \\
\hline Male & 45.1 & 45.5 & 45.2 & 45.2 & 45.3 \\
Female & 33.2 & 34.7 & 34.2 & 33.5 & 34.0 \\
All & 40.6 & 41.1 & 40.4 & 39.9 & 40.0 \\
\hline
\end{tabular}

Underlying these changes in total hours for males and females overall have been major shifts in the total hours worked by some age groups (Table 2 ). The total hours worked by males aged 15 to 19 decreased from 39.3 in 1981 to 29 in 2001 and females from 35.3 to 21.8 . There was a smaller corresponding decrease in hours worked by males and females aged 20 to 24 . Total hours worked increased for both males and females for all other age groups between 1981 and 2001 . The largest increase in hours work by employed women was from 32.7 to 36.7 hours for those aged 45 to 49 and 32.4 to 36.6 hours for those aged 50 to 54 . Total hours worked by employed males also increased most amongst males aged 45 and over.

Table 2: Male and female mean total hours by age, 1981 and 2001.

\begin{tabular}{lllll} 
& Male & \multicolumn{3}{c}{ Female } \\
& 1981 & 2001 & 1981 & 2001 \\
\hline $15-19$ & 39.3 & 29.0 & 35.3 & 21.8 \\
$20-24$ & 43.7 & 41.6 & 37.8 & 35.0 \\
$25-29$ & 45.9 & 45.7 & 33.5 & 37.3 \\
$30-34$ & 47.2 & 47.1 & 30.1 & 34.5 \\
$35-39$ & 47.9 & 47.9 & 31.0 & 33.2 \\
$40-44$ & 47.8 & 48.4 & 32.3 & 34.7 \\
$45-49$ & 47.0 & 48.7 & 32.7 & 36.7 \\
$50-54$ & 46.0 & 48.4 & 32.4 & 36.6 \\
$55-59$ & 44.5 & 46.9 & 32.1 & 34.4 \\
$60-64$ & 41.0 & 43.3 & 29.7 & 31.1 \\
15 plus & 45.1 & 45.3 & 33.2 & 34.0 \\
\hline
\end{tabular}

\section{Trends in Total Hours Worked by Multiple Job Holders}

Total hours worked and hours worked by multiple job holders have followed a similar overall trend over the 1981 to 2001 period (Table 3).

Those holding multiple jobs in 2001 worked on average 47 hours compared with only 39.2 hours for others (Table 3 ). The difference between hours worked by multiple job holders and others peaked at 9.4 hours in 1986 but dropped to 5.4 hours in 1991, 5.9 hours in 1996, before widening to 7.8 hours in 2001 .

Over the 1981 to 2001 period. The difference between total hours worked by male multiple job versus nonmultiple job holders has in most cases been larger than between female multiple job holders and others (Table 4 ). 
In 2001, male multiple job holders worked 9.5 hours more than males with only one job.

Table 3: Trends in mean total hours worked by multiple job holding status 1981 to 2001.

\begin{tabular}{llllc} 
& \multicolumn{4}{c}{ Multiple Job Holding Status } \\
& Yes & No & All & Difference \\
\hline 1981 & 48.0 & 40.3 & 40.6 & 7.7 \\
1986 & 50.0 & 40.6 & 41.1 & 9.4 \\
1991 & 45.4 & 40.0 & 40.4 & 5.4 \\
1996 & 45.2 & 39.3 & 39.9 & 5.9 \\
2001 & 47.0 & 39.2 & 40.0 & 7.8 \\
\hline
\end{tabular}

Table 4: Difference between mean total hours of multiple job holders and non multiple job holders, males and females, 1981 to 2001.

\begin{tabular}{llllll} 
& 1981 & 1986 & 1991 & 1996 & 2001 \\
\hline Male & 9.3 & 9.7 & 7.2 & 8.6 & 9.5 \\
Female & 3.9 & 10.2 & 5.3 & 5.1 & 6.9 \\
\hline
\end{tabular}

\section{Multiple Job Holding Rates by Women with Young Children}

The statistics presented cross-tabulate the age of the youngest child in the household with the multiple job holding status of each woman in that household. This linkage of women with the children in the household will generate a proportion of mismatches correlated with the age of the woman. In order to reduce the number of instances where women are incorrectly assumed to be the parent of the youngest child in the household, only those statistics for women aged 20 to 34 years are considered here.

Multiple job holding rates amongst women in all three of the five year age bands peaked in 1996 (Table 5). Multiple job holding rates for women in houscholds with a child under two were lowest at age 20 to 24 and increased up to the 30 to 34 year age group for all census from 1981 to 2001 . From 1996, multiple job holding rates amongst women aged 25 to 29 were lower than for women aged 20 to 24 and those aged 30 to 34 years.

The net effect of this is that women aged 20 to 24 in households with children under two were less likely than others to be multiple job holders. By contrast, from 1986, women aged 25 to 29 in households with children under two were more likely to be multiple job holders. The results were not conclusive for women aged 30 to 34 years with children under two more likely to be multiple job holders in 2001, but marginally less likely to be multiple job holders for previous years.

What sorts of effect does occupation and associated socio-economic status have on multiple job holding behaviour of women living in households with children under two versus others? For this the statistics available to this analysis are for women aged 20 to 29 years. As a preliminary to that discussion, what are the rates of multiple job holding for women aged 20 to 29 with children under two? Women aged 20 to 29 years living in a household with children under two were in net less likely to be multiple job holders than others by a small margin for 1981 through to 2001 (Tables 6 and 7). This aggregated statistic reflects the larger number of women with children aged 25 to 29 than aged 20 to 24 .

Table 8 shows that the 2001 multiple job holding rates for women aged 20 to 29 living in a household with a child under two vary from a low $5.7 \%$ for "'labourers and related elementary workers" to a high of $16.7 \%$ for "market oriented agricultural and fishery workers" (Table $8)$. The differences between the rates of multiple job holding for women aged 20 to 29 living in a household with a child under two and those living in a household with a child aged over 4 or no children ranged from an increased multiple job holding rate of $4.6 \%$ for "market oriented agricultural and fishery workers" to a $2.7 \%$ lower multiple job holding rate for "personal and protective service workers".

Table 5: Trends in the multiple job holding rates by age of woman and age of youngest child in the household, 1981 to 2001.

\begin{tabular}{lllllll}
\hline $\begin{array}{l}\text { Age of } \\
\text { Women }\end{array}$ & $\begin{array}{l}\text { Age of Youngest } \\
\text { Child }\end{array}$ & 1981 & 1986 & 1991 & 1996 & 2001 \\
\hline $20-24$ yrs & Less than 2 & 2.7 & 4.0 & 5.5 & 9.4 & 6.5 \\
& $\begin{array}{l}\text { All Women } \\
\text { Difference }\end{array}$ & 3.5 & 5.4 & 6.8 & 10.8 & 8.5 \\
& & & 1.4 & 1.3 & 1.3 & 2.0 \\
\multirow{2}{*}{$25-29 \mathrm{yrs}$} & Less than 2 & 3.7 & 5.7 & 8.1 & 10.9 & 8.9 \\
& All Women & 4.4 & 5.5 & 7.0 & 9.5 & 7.4 \\
& Difference & 0.6 & -0.2 & -1.1 & -1.4 & -1.5 \\
$30-34 \mathrm{yrs}$ & & & & & 11.2 & 11.0 \\
& Less than 2 & 4.7 & 6.3 & 9.1 & 11.6 & 9.1 \\
& All Women & 5.5 & 6.7 & 9.3 & 0.4 & -1.9 \\
\hline
\end{tabular}


Table 6: Trends in the multiple job holding rates for 20-29 year old women by age of youngest child in the household, 1981 to 2001.

\begin{tabular}{llllll}
\hline Age of Youngest Child & 1981 & 1986 & 1991 & 1996 & 2001 \\
\hline Less than 2 & 3.3 & 4.0 & 7.3 & 10.5 & 8.1 \\
2-4 years old & 4.3 & 4.6 & 8.0 & 10.8 & 7.4 \\
Greater than 4 & 4.3 & 4.7 & 7.4 & 11.8 & 8.5 \\
\hline
\end{tabular}

Table 7: Difference between multiple job holding rates of 20-29 year old women by age of youngest child in the household and households where there are no children or the youngest child is older than 4 years, 1981 to 2001.

\begin{tabular}{llllll}
\hline Age of Youngest Child & 1981 & 1986 & 1991 & 1996 & 2001 \\
\hline Less than 2 years & -0.9 & -0.7 & -0.1 & -1.3 & -0.4 \\
2-4 years old & 0.0 & -0.1 & 0.6 & -1.0 & -1.1 \\
\hline
\end{tabular}

Table 8: Increase in multiple job holding rates by occupation for women aged 20 to 29 in households with a child aged under 2 compared with women in households with no child or the youngest child aged over 4 years in 2001.

\begin{tabular}{llll}
\hline Occupation - NZSCO based derivative - level 2 & NZSEI 96 & $\begin{array}{l}\text { Multiple Job } \\
\text { Holding Rate (\%) }\end{array}$ & Increase in Rate \\
\hline Life Science and Health Professionals & 71 & 8.2 & 1.2 \\
Other Professionals & 71 & 9.9 & 3.3 \\
Teaching Professionals & 69 & 8.2 & -2.3 \\
Corporate Managers & 57 & 9.0 & 2.8 \\
Other Associate Professionals & 56 & 9.6 & -0.4 \\
Office Clerks & 43 & 8.2 & -0.2 \\
Customer Services Clerks & 41 & 6.6 & -1.0 \\
Personal and Protective Services Workers & 38 & 7.0 & -2.7 \\
Salespersons, Demonstrators and Models & 33 & 8.1 & -2.1 \\
Labourers and Related Elementary Service Workers & 31 & 5.7 & -1.0 \\
Market Oriented Agricultural and Fishery Workers & 25 & 16.7 & 4.6 \\
All Occupations & - & 8.1 & -0.4 \\
\hline
\end{tabular}

Table 9: Increase in multiple job holding rate by occupation of women aged 20 to 29 in households with a child aged under 2 compared with women in households with no child or youngest child aged over 4 years, 1981 to 2001.

\begin{tabular}{llllll}
\hline Occupation - NZSCO based derivative - level 2 & 1981 & 1986 & 1991 & 1996 & 2001 \\
\hline Life Science and Health Professionals & 1.2 & 2.7 & -0.4 & 4.3 & 1.2 \\
Other Professionals & -0.1 & -3.9 & 1.7 & 1.6 & 3.3 \\
Teaching Professionals & -2.8 & -2.0 & 1.5 & 0.4 & -2.3 \\
Corporate Managers & -0.4 & 1.5 & -2.6 & 1.0 & 2.8 \\
Other Associate Professionals & 0.4 & -0.3 & -0.8 & -0.2 & -0.4 \\
Office Clerks & -0.6 & -0.7 & 0.4 & -1.3 & -0.2 \\
Customer Services Clerks & -1.8 & -1.4 & -0.9 & -2.3 & -1.0 \\
Personal and Protective Services Workers & -1.3 & -2.0 & -3.6 & -4.7 & -2.7 \\
Salespersons, Demonstrators and Models & -1.0 & 0.1 & -0.4 & -2.4 & -2.1 \\
Labourers and Related Elementary Service Workers & -1.1 & -0.8 & -0.9 & -2.7 & -1.0 \\
Market Oriented Agricultural and Fishery Workers & -1.7 & 0.2 & 2.7 & -1.0 & 4.6 \\
All Occupations & -0.9 & -0.7 & -0.1 & -1.3 & -0.4 \\
\hline
\end{tabular}

What is interesting is that there appears to be a socioeconomic status dimension to this variation in multiple job holding rates (Table 8). It appears that women aged 20 to 29 working in professional occupations (except teaching) with a child under two are more likely to be multiple job holders compared with households where the youngest child is over four or there are no children. Where such women with children under two are engaged in their professions they are more likely to do so as multiple job holders than other women. By contrast, women aged 20 to 29 years working in other occupations (with the notable exception of women working in farming occupations) and living in a household with a child under two were less likely to be multiple job holders than others. 


\section{Discussion}

This paper reports a limited initial case study on work-life balance tradeoffs using the census derived statistical time series developed for the multiple job holding project. It complements and supplements the more qualitative information on work-life balance issues gathered in the sectoral case studies. It also explores ideas on work-life balance and is used to guide a more in depth analysis of 2001 census derived patterns of multiple job holding within households. The contingent circumstances and motivational tradeoffs associated with any individual's decision to become a multiple job holder are complex, as the results presented here demonstrate.

An analysis of the combinations of factors associated with variations in multiple job holding in the population provides ways of testing different motivational models of observed multiple job holding rates. This paper considers work-life balance tradeoffs for multiple job holding as a work participation strategy.

Engagement in multiple job holding is a trade off of increased income and increased diversity of work against longer hours and other work-life balance consequences. Analysis of census data suggest that these early years of parenting, particularly amongst younger mothers. generally makes the adoption of the multiple job holding work strategy more difficult to achieve. That this is not always the case is demonstrated by the occupational breakdown, which suggests that professional women (on higher incomes) and farming women (work flexibility and presence at home) in this age band and early stage of parenting are indeed more likely than other women of similar age to adopt a multiple job holding work strategy.

\section{Further Research}

This paper is an exploration of an approach using a limited set of data. This exploratory analysis relied on the age of the youngest child in the household. As a result the analysis has been constrained to those households where there is high certainty of association of women with those children resident in the household - judged to be those age 20 to 29 years.

A more precise and robust indicator of direct child to male or female parent dependency can be estimated from the population census using the youngest person in the same family nucleus as any particular individual with a parental role. In a two parent family unit, the working hours across both parents could be taken into account. The working hours and incomes outcomes associated with the choice to seek more than one job could be analysed directly rather than inferred indirectly. That extension to the analysis would allow the tradeoffs to be explored across the full range of age and sex of parent.

\section{Notes}

I Working papers and other results from the research programme can be found at: www.tba.co.nz/fist projects frstproject tbsx0204 html.
A quote from the introductory web page on the New

Zealand work-life balance project

(www.dol.govt.nzlworklifelindex.asp)

\section{References}

Baines, J. and Newell, J. (2005). Trends in the New Zealand labour market, non-standard work and multiple job holding 1981-2001. Working Paper No. 11, Multiple Job Holding in New Zealand. Christchurch: Taylor Baines and Associates available at www.tba.co.nz/frst projects/ frstproject_tbsx0204.html.

Callister, P. (2005). Overworked families? Changes in the paid working hours of families with young children, 1986 to 2001. Social Policy Journal of New Zealand, 24, 160184.

McClintock, W., Taylor, N and Warren, J. (2004). Effects of Multiple Job Holding on the Work-life Balance. 1lth Lahour: Emplosment and Work in New Zealand Conference, Wellington.

Taylor, N., Baines, J and Newell, J. (2006). The Potential Influence of Multiple Job Holding on Official Statistics Descrihing the Rural Workforce: Issues for Data Series and Workforce Policy. Paper presented at the New Zealand Agricultural and Resource Economics Society Conference. Nelson, August 2006.

UMR Research. (2003). Perceptions and attitudes towards worklife balance in New Zealand. A Qualitative Study. Report to the Ner. Zealand Department of Labour.

Women's Affairs. (2002a). Participation in paid work of mothers with a youngest child aged under five vears. New Zealand Ministry of Women's Affairs web report, August 2002

Women's Affairs. (2002b). Work and family balance : a policy perspective. New Zealand Jurisdictional Report to the WAM WOM Work and Family Workshop Sydney, 25 March 2002.

\section{Authors}

James Newell

Director

Monitoring and Evaluation Research Associates Ltd

P.O. Box 2445

Wellington

Jnewell $u$ mera.co.nz

James Baines

Director

Taylor Baines \& Associates

P.O. Box 860

Riccarton

Christchurch

J.Baines $a$ tba.co.nz 